\title{
Could Immunity Boosting Therapy help COVID-19 Patient?
}

\author{
Kieu C D Nguyen ${ }^{1 *}$, Mario G Balzanelli², Pietro Distratis ${ }^{3}$, Rita Lazzaro ${ }^{3}$, Orazio Catucci ${ }^{3}$, Angelo \\ Cefalo $^{3}$, Davide Palazzo ${ }^{3}$, Giuseppe D Angela $^{3}$, Felice Amatulli ${ }^{3}$, C Isacco Gargiulo ${ }^{3}$, Diego \\ Tomassone ${ }^{4}$, Sergey Aityan ${ }^{5}$ and Van H Pham ${ }^{6}$
}

${ }^{1}$ American Stem Cells Hospital JSC and Human Stem Cells Institute (HSC), Vietnam

${ }^{2}$ SET-118, Department of Pre-hospital and Emergency S Giuseppe Moscati Hospital, Italy

${ }^{3}$ SET-118, Department of Pre-hospital and Emergency S Giuseppe Moscati Hospital, Italy

${ }^{4}$ Nutri Therapy Research Center, Italy

${ }^{5}$ Department of Multidisciplinary Research Centre, Lincoln University, USA

${ }^{6}$ International Gene and Immunology Institute and Nam-Khoa Biotek, Vietnam

*Corresponding author: Kieu C D Nguyen, Department of Pre-hospital and Emergency - S. Giuseppe Moscati Hospital, Taranto City, 74100, Italy and American Stem Cells Hospital JSC. and Human Stem Cells Institute (HSC), Ho Chi Minh City, 70000, Vietnam

\section{ARTICLE INFO}

Received: 蔧 August 11, 2020

Published: 幽 September 08, 2020

Citation: Kieu CDNguyen, Mario G Balzanelli, Van HPham, Isacco CGargiulo. Could Immunity Boosting Therapy help COVID-19 Patient?. Biomed J Sci \& Tech Res 30(1)-2020. BJSTR. MS.ID.004908.

\section{ABSTRACT}

The SARS-CoV-2 and other members of the same coronavirus family from Wuhan, China in late December 2019 or the coronavirus disease 2019 (COVID-19)pandemic is a challenge for globalhealthcare systems in thisdecade. The combination of using antiretroviral therapy and antibiotics in pneumonia inflammation and immunity boosting therapyin this case reportsuccessfully could help COVID-19 patient.

Keywords: SG Moscati Hospital; 118 Pre-Hospital Medical System-Emergency Department; COVID-19, Sars-CoV-2

\section{Case Report}

In Feb 22, 2020, 58 years old American -Vietnamese oversea woman living in San Jose, California, United States of America,with her husband and theirdaughter attended a birthday party of forty people. She got sick after 5 days. She felt shudders in her body, tired with fever $39^{\circ} \mathrm{C}$ and nausea, dry cough, malaise,dyspnea and respiratory distress, shortness of breath,headache, sore throat,fatigue and loss of taste. Her condition was not improved even she took some pills of Tylenon. She had not severe underlying medical condition like heart or lung disease or diabetes. She and her husbandboth had immunity boosting bymulti - vitamin therapy such as injection of Vitamin B, D, K, and laroscorbineinfussionin January 2020 at Ho Chi Minh city, Vietnam. On March 06, 2020 in Kaser Permanentehospital,she was isolated in emergency roomfor bloodanalysisand thetampon throatswab buffer (oral - nasal-pharinx by RT-PCR) obtained from this patient test positive for SARS nCoVafter two days. The symptoms associated with acute respiratory distress was confirmed by $\mathrm{x}$ ray result positive that showed inflammation in herboth lungs.She was transmitted to pneumonia department and treated with antiviral agents, antibiotics for respiratory infection, and supportive therapies.

This therapy strategy consisted of targeting viral and bacterial infection. Her fever disappeared after 2 dayson March 08, 2020 and she was quicklyrecoveredand discharged from hospital after four days. She was completely recovered in the end of March 29, 2020 without coughing, no more nausea, taste returnedon all food. Her husband 68 years old who was with her in that partyhad no symptoms of illness and did not test for Covid-19. He got orderedto be self-quarantined in their housefor 2 weeks.On June 18, 2020 
he did blood test and result of Negative for CoVID-19 Ab, IgG (CoVID-19 Ab, Interpretation) Not detected.Her daughter 28 years old who was her in that party had mild fever and got some pills of Tylenon for 2 days. Her grandson 3 years old got mild fever and treated withTylenon for 2 days. Her daughter and her grandson got themselves quarantined at her daughter'shouse in 2 weeks without hospitalization.Her son in law 35 years old who lives with her daughter and her grandson, had no symptom and got himself quarantined at her daughter's house in 2 weeks without hospitalization.

\section{Medication}

The treatment was basedon the use of Cefpodoxime (VANTIN) 200 mg, Doxycycline Monohydrate (AVIDOXY) 100 mg,Kaletra

\section{ISSN: 2574-1241}

DOI: $10.26717 /$ BJSTR.2020.30.004908

Kieu CDNguyen. Biomed J Sci \& Tech Res

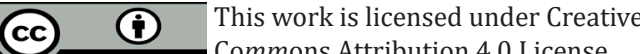

Submission Link: https://biomedres.us/submit-manuscript.php
(Lopinavir and Ritonavir), Ritonavir( NORVIR ) 100mg and Prezista ( DARUNAVIR ) 600mg high flow oxygen therapy and high restrictive fluid management.

\section{Conclusion}

In general,the X-Ray or CT scan resulted to be more accurate than the swabs, considered sign for an immediate hospitalization in specific departments before developing more complications from COVID-19 illness. The majority of the suspected COVID-19 healthy patients were promptly treatedsuccessfully with the combination of using antiretroviral therapy and antibiotics after 5 weeks with relieved symptoms.

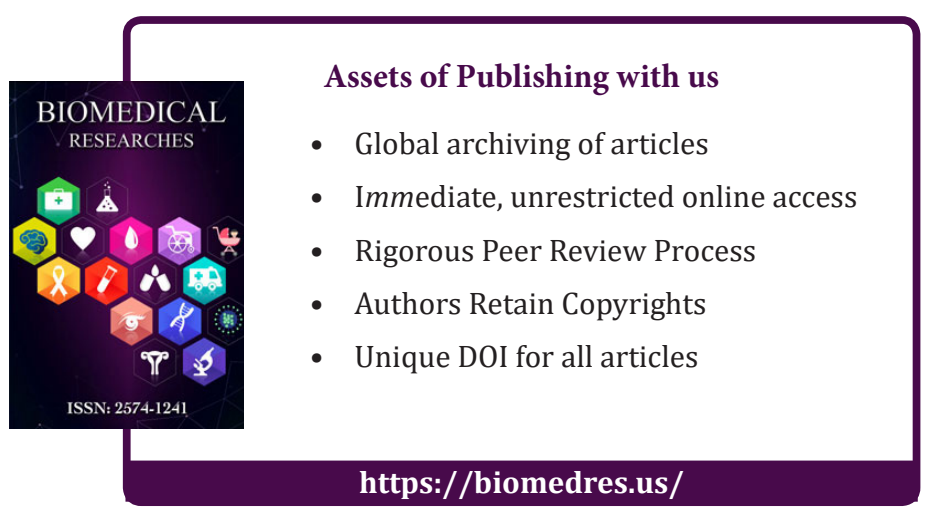

